\title{
Relationship between angiogenic squamous dysplasia and bronchogenic carcinoma in patients undergoing white light bronchoscopy
}

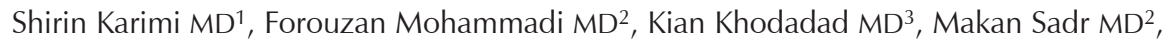 \\ Leila Seyfollahi MD' ${ }^{1}$, Mohammad Reza Masjedi MD³
}

\begin{abstract}
S Karimi, F Mohammadi, K Khodadad, M Sadr, L Seyfollahi, MR Masjedi. Relationship between angiogenic squamous dysplasia and bronchogenic carcinoma in patients undergoing white light bronchoscopy. Can Respir J 2012;19(3):201-208.
\end{abstract}

OBJECTIVE: To better understand the characteristic morphology of angiogenic squamous dysplasia (ASD) and its association with different types of common bronchogenic carcinomas using routine white light bronchoscopy. METHODS: Using a case-control design, 186 formalin-fixed paraffinembedded blocks of bronchial tissue ( 136 cases, 50 controls) obtained from patients who underwent routine nonfluorescence bronchoscopy between 2004 and 2005 were studied.

RESULTS: ASD occurred at a higher frequency in patients with neoplastic lesions compared with those without neoplastic lesions ( 28 of 136 versus one of 50). ASD was also more prevalent in patients with squamous cell carcinoma compared with other neoplasms. Seventy six per cent of the ASD patients (22 of 29) smoked cigarettes. The morphology of ASD on hematoxylin and eosin- and CD31-stained sections was characterized by prominent microvasculature and capillary projections closely juxtaposed to variable degrees of dysplasia in all of the bronchogenic carcinoma specimens, and to metaplasia in one case in the control group.

CONCLUSION: ASD is a unique morphological entity that should be considered by pathologists even on bronchoscopic biopsies from patients who undergo white light bronchoscopy. The presence of ASD may represent a risk biomarker of bronchogenic carcinoma in screening programs and in chemoprevention of lung cancer.

Key Words: Angiogenic squamous dysplasia; Bronchogenic carcinoma; Bronchoscopy; Fluorescence; Immunohistochemistry

L ung cancer remains the most lethal human neoplasm, accounting for $29 \%$ of all cancer deaths (1). The majority of patients $(80 \%)$ already have advanced and inoperable disease when they present to their physicians (2,3). The overall five-year survival rate for lung cancer is approximately $15 \%$ and has improved only marginally over the past 30 years (1). Cancer has become the third major cause of death in Iran after cardiovascular disease and accidents (4). Moreover, lung cancer is one of the five leading tumours in Iran, and the rate has been increasing steadily in both men and women, similar to trends in southern and eastern Europe (5).

The concepts that underpin solid tumour carcinogenesis have led to strategies for early detection of these lesions. Many morphological and molecular abnormalities present in invasive tumours also occur in pre-invasive epithelial lesions to a lesser degree, particularly in squamous cell carcinoma (SCC); this finding has led to the concept that premalignancy can be regarded as the disease and carcinoma as the end point.

The classic WHO classification of premalignant lesions in bronchial epithelium (6) includes seven categories based on microscopic

\section{La relation entre la dysplasie malpighienne angiogénique et le carcinome bronchique chez des patients qui subissent une bronchoscopie en lumière blanche}

OBJECTIF : Mieux comprendre la morphologie caractéristique de la dysplasie malpighienne angiogénique (DMA) et son association avec divers types de carcinomes bronchiques courants au moyen de la bronchoscopie à lumière blanche systématique.

MÉTHODOLOGIE : Au moyen d'une étude cas-témoins, les chercheurs ont étudié 186 blocs de tissus bronchiques fixés au formol et inclus en paraffine (136 cas, 50 témoins) prélevés sur des patients qui avaient subi systématiquement une bronchoscopie sans fluorescence entre 2004 et 2005.

RÉSULTATS : La DMA était plus fréquente chez les patients ayant des lésions néoplasiques que chez ceux qui n'en avaient pas (28 sur 136 par rapport à une sur 50). Elle était également plus prévalente chez les patients ayant un carcinome spinocellulaire que chez ceux ayant d'autres néoplasmes. Soixante-seize pour cent des patients ayant une DMA (22 sur 29) fumaient la cigarette. La morphologie de la DMA dans des coupes colorées à l'hématoxyline-éosine et au CD31 se caractérisait par une importante microvascularisation et par des projections capillaires étroitement juxtaposées à divers degrés de dysplasie dans tous les échantillons de carcinome bronchique et, dans un cas du groupe témoin, de métaplasie.

CONCLUSION : La DMA est une entité morphologique unique que les pathologistes devraient envisager même sur les biopsies bronchoscopiques de patients qui subissent une bronchoscopie en lumière blanche. La présence de DMA peut constituer un biomarqueur de risque de carcinome bronchique dans les programmes de dépistage et la chimioprévention du cancer du poumon.

features including normal histology, reverse cell hyperplasia, mild, moderate and severe dysplasia, and carcinoma in situ. In addition to changes in the bronchial epithelium, changes in the stromal support tissue, especially angiogenesis, have also been described. Recently, the importance of tumour-associated angiogenesis has been highlighted by numerous reports of considerable decrease in tumour growth subsequent to anti-angiogenic therapy. However, in the case of premalignant conditions, there are little available data (7).

Recently, the detection of dysplastic lesions in the large airways has been improved by using fluorescence bronchoscopy. Fluorescence bronchoscopy has also helped in the identification of angiogenic squamous dysplasia (ASD), a new morphological entity $(8,9)$. In 1983 , Muller and Muller (10) recognized that "micropapillomatosis occurred in bronchial epithelium dysplasia" and suggested a possible link between angiogenesis and preinvasive bronchial epithelial dysplasia. They also described the ultrastructure of such lesions. This angiogenesis is characterized by capillary loops projecting into the dysplastic bronchial lining and it is believed that these microvessels may be responsible for the reduced fluorescence seen in dysplastic lesions during fluorescence

${ }^{1}$ Department of Pathology, Mycobacteriology Research Center; ${ }^{2}$ Tracheal Diseases Research Center; ${ }^{3}$ Chronic Respiratory Disease Research

Center, National Research Institute of Tuberculosis and Lung Disease, Shahid Beheshti University of Medical Sciences, Tehran, Iran

Correspondence: Dr Kian Khodadad, Department of Thoracic Oncology, Masih Daneshvari Hospital, National Research Institute

of Tuberculosis and Lung Disease, Shaheed Bahonar Avenue, Darabad, Tehran 19556, Iran. Telephone 98-21-27122201,

fax98-21-26109946,e-mail kiankhodadad@yahoo.com, kkhodadad@nritld.ac.ir 
TABLE 1

Comparison of angiogenic squamous dysplasia (ASD) presence between neoplastic and non-neoplastic lesions

\begin{tabular}{lccc} 
& \multicolumn{2}{c}{ Lesions } & \\
\cline { 2 - 3 } ASD & Neoplastic & Non-neoplastic & Total \\
\hline Present & $28(20.6)$ & $1(2)$ & $29(15.6)$ \\
Absent & $108(79.4)$ & $49(98)$ & $157(84.4)$ \\
Total & $136(73.1)$ & $50(26.9)$ & $186(100)$ \\
\hline
\end{tabular}

Data presented as $n$ (\%)

bronchoscopy. More prospective investigations are needed to evaluate whether this morphological entity is associated with progression to lung cancer. If such a correlation is confirmed, ASD would be an ideal target for anti-angiogenic agents used for chemoprevention (9).

Potentially, the most significant stromal change in a premalignant bronchial lesion may be microscopic evidence of neoangiogenesis, referred to as ASD (8). It has been shown that autofluorescence bronchoscopy (AFB) is sufficiently sensitive to diagnose preneoplastic lesions in central airways (11). ASD is easily recognized by AFB and is characterized by the sprouting of capillaries into dysplastic or metaplastic squamous mucosa. ASD can be also detected by white light bronchoscopy (WLB), but with less accuracy compared with AFB.

ASD may present as multifocal lesions and may persist for several years at the same site. ASD has been reported to be preferentially associated with bronchogenic carcinoma, especially SCC (12).

To better understand the prevalence of ASD in association with different types of bronchogenic carcinomas and to describe its characteristic morphological abnormalities during lung carcinogenesis, we performed a retrospective study on bronchial biopsy specimens from our pathology department, which were obtained during routine WLB from patients with bronchogenic carcinoma.

\section{METHODS}

\section{Specimens}

Specimens were formalin-fixed, paraffin-embedded blocks obtained from bronchial biopsies of 136 patients with bronchogenic carcinoma who had undergone diagnostic routine WLB. The biopsies were obtained from the site of the tumour and from the surrounding bronchial mucosa. Fifty control bronchial specimens from patients with non-neoplastic lung disease were also examined. These were obtained from patients who underwent WLB for another reason (eg, infection). The number of tissue fragments from each biopsy ranged from two to four. The final diagnoses for the 136 patients with malignancy were as follows: SCC, $n=56$ (41\%); adenocarcinoma (ADC), $n=39$ (29\%); small cell carcinoma (SMCC), n=32 (23.5\%); and undifferentiated nonSMCC, $n=9(7 \%)$. Patients with bronchogenic carcinoma included $112(82 \%)$ men and $24(18 \%)$ women ranging in age from 35 to 85 years (mean $[ \pm \mathrm{SD}] 61.5 \pm 10.6$ years). The 50 subjects who had non-neoplastic specimens consisted of $32(64 \%)$ men and $18(36 \%)$ women with an age range of 21 to 80 years (mean $57.7 \pm 16.3$ years).
Histopathology

All biopsies were fixed in $10 \%$ buffered formalin and embedded in paraffin wax. Paraffin blocks were sectioned into $5 \mu \mathrm{m}$ slices according to a standard protocol, and serial slices were mounted on glass slides. Between one and four slides containing three sections/slide were prepared from each paraffin block. Slides were stained with hematoxylin and eosin (H\&E) and examined for histological diagnosis by a pathologist (FM). The WHO classification for premalignant lesions was used $(6,13)$.

Each biopsy was microscopically re-evaluated for confirmation of the diagnosis of carcinoma and classification of preneoplastic lesions in nonmalignant mucosal fragments. Each biopsy was classified as no epithelial abnormality, basal cell hyperplasia, squamous metaplasia, dysplasia (severe, moderate and mild) and ASD.

ASD was defined according to previous studies as "hyperplastic capillary loops in close apposition (closely juxtaposed) to dysplastic or metaplastic epithelium and/or by sprouting of capillaries into dysplastic squamous mucosa" (8,14-16).

\section{CD31 immunohistochemical staining}

Endothelial cells were identified in tissue sections by immunohistochemical (IHC) staining using the endothelial marker CD31. This marker was used to highlight the presence of capillary cores in the ASD lesions. To demonstrate this antigen, a subset of paraffin sections was stained using mouse anti-CD31 antibody (DAKO, USA) and visualized using a commercially available kit (LSAB2 [DAKO, USA]). Twenty-nine cases with ASD underwent IHC analysis for CD31. The results were reviewed by the first author (SK) and confirmed by a pathologist (FM).

\section{Statistical analysis}

Statistical analyses were performed using SPSS version 16 (IBM Corporation, USA). The $\chi^{2}$ test was used to compare the frequency of variables in different groups. $\mathrm{P}<0.05$ was considered to be statistically significant.

\section{RESULTS}

ASD was detected in 28 of 136 bronchogenic carcinoma specimens and in one of 50 control bronchial biopsies. There was a significant difference in the presence of ASD between neoplastic cases and nonneoplastic cases $(20.6 \%$ versus $2 \% ; \mathrm{P} \leq 0.001)$ (Table 1 ).

The frequency of ASD was 41\% (23 of 56), 12.5\% (four of 32), $2.5 \%$ (one of 39 ) and $0 \%$ (zero of nine) in patients with SCC, SMCC, ADC and undifferentiated non-SMCC, respectively.

Among 28 cases with neoplasm who also had ASD, 23 were from patients with SCC (82\%), four with SMCC (14\%) and one with ADC $(3.5 \%)$. There was a significant relationship between ASD and SCC compared with the other three carcinomas $(\mathrm{P} \leq 0.001)$. The morphological changes of bronchial epithelium in each neoplasm are shown in Table 2.

Among patients with bronchogenic carcinoma with or without ASD, there were no significant differences in age and sex. Twenty-two of 29 cases $(76 \%)$ were cigarette smokers.

The morphology of ASD in H\&E- and CD31-stained sections was microscopic papillomatosis of the bronchial epithelium associated

\section{TABLE 2}

Morphological changes in bronchial biopsies of patients with bronchogenic carcinoma

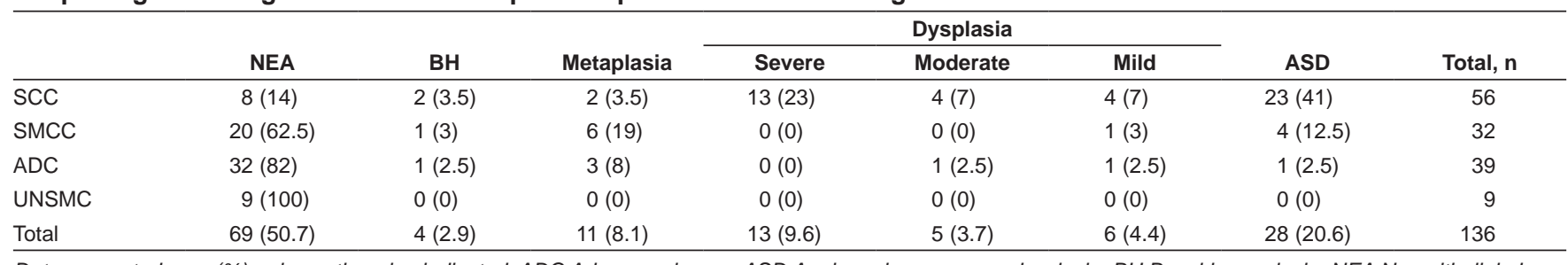

Data presented as $n$ (\%) unless otherwise indicated. ADC Adenocarcinoma; ASD Angiogenic squamous dysplasia; BH Basal hyperplasia; NEA No epithelial abnormality; SCC Squamous cell carcinoma; SMCC Small cell carcinoma; UNSMC Undifferentiated non-SMCC 


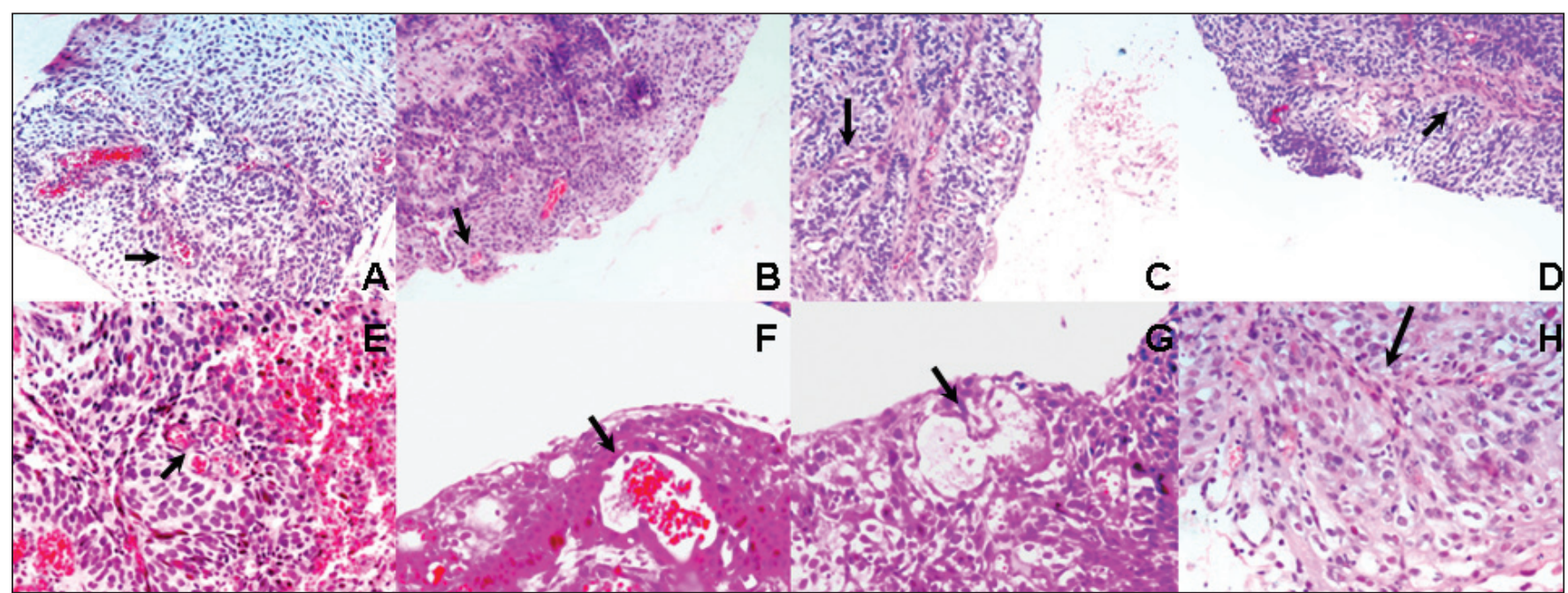

Figure 1) Angiogenic squamous dysplasia cases. Intraepithelial sprouting of capillaries (arrows) in dysplastic squamous epithelium associated with papillomatosis (A and $\mathbf{B}$ [original magnification $(\mathrm{OM}) \times 10], \mathrm{F}$ and $\mathrm{G}[\mathrm{OM} \times 40]$ ). Juxtaposition of neoformed capillaries to the basal membrane $(\mathbf{C}$ and $\mathbf{D}[\mathrm{OM} \times 10])$ and subepithelial proliferation of capillaries in the absence of a basal membrane in dysplastic squamous epithelium ( $\mathrm{E}$ and $\mathbf{H})$ (arrows) $\mathrm{OM} \times 40$, hematoxylin and eosin stain

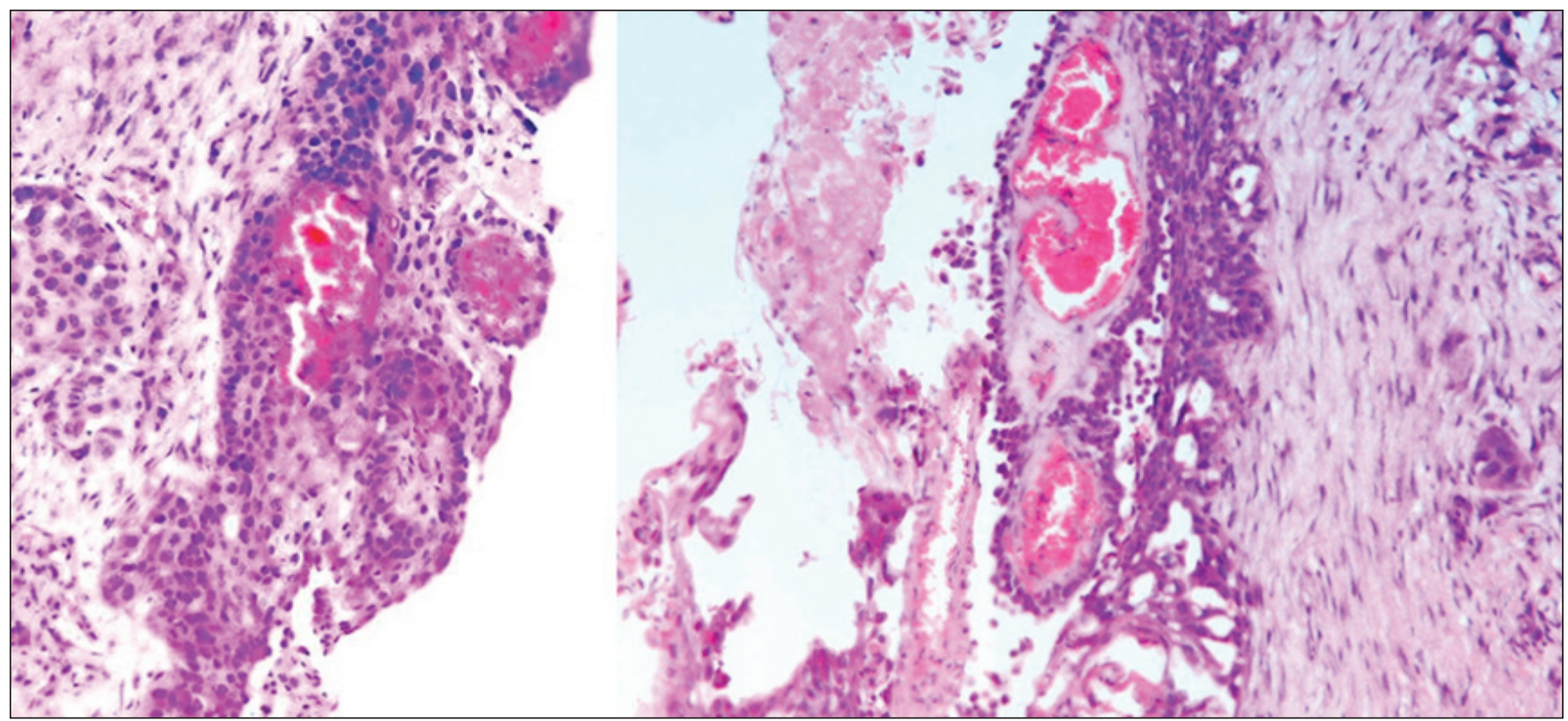

Figure 2) Metaplasia in one case in the control group. Hematoxylin and eosin stain, original magnification $\times 40$

with prominent microvasculature and capillary projections closely juxtaposed to variable degrees of dysplasia of the bronchial epithelium in $24(83 \%)$ cases (Figures $1 \mathrm{~A}$ to $1 \mathrm{H}$ ) and to metaplasia in one case in the control group (Figure 2). A thickened basal membrane was seen in only four of $29(14 \%)$ of the ASD cases. Some of the ASD cases revealed vascular wall hyalinization (Figure 3 ), and the others revealed marked dilation and congestion (Figure 4). CD31 highlighted the protrusion of capillaries into the dysplastic epithelium (Figure 5).

\section{DISCUSSION}

The novel finding of our study was the demonstration of the characteristic morphological features of ASD in bronchial biopsies of a substantial number of patients who underwent WLB, in addition to others. In the present study, there was a significant correlation between ASD and SCC compared with other non-SMCCs. This result is similar to the study by Keith et al (12), who also showed preferential association of ASD with SCC rather than ADC.

ASD has not been reported to be present in the normal bronchial tree. In a previous study, the lesion was not present in biopsies of 16 nonsmoking control subjects (8). Concordant with this, we found only one case of ASD in our control group who demonstrated accompanying squamous metaplastic changes.

Keith et al (8) reported no statistical difference in age and sex between individuals with and without ASD lesions. In our study, there were no significant differences in age and sex between the patients with and without ASD.

Regarding the detection of ASD in the bronchial tree, it has been reported that the sensitivity of detecting high-grade dysplasia and carcinoma in situ is $80 \%$ (range $43 \%$ to $100 \%$ ) for AFB and $40 \%$ (range $9 \%$ to $78 \%$ ) for WLB (1).

Keith et al (8) reported that $59 \%$ of airways with ASD were abnormal under fluorescent light bronchoscopic examination but normal under white light (8).

The decrease of autofluoroscence intensity is probably due to a variety of factors such as biochemical changes, thickness of the epithelium and microvascular density of the subepithelial layer (17).

Therefore, the prevalence of ASD detected bronchoscopically will undoubtedly increase by combining the new generation of 


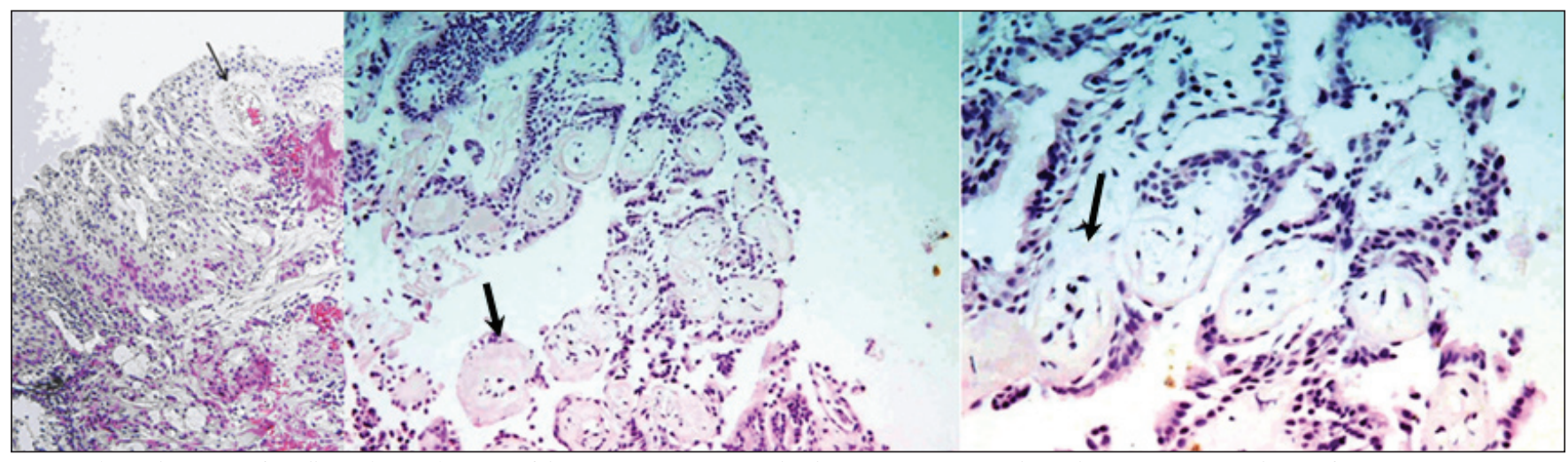

Figure 3) Hyalinization of capillaries (arrows) in one of the angiogenic squamous dysplasia cases. Hematoxylin and eosin stain, original magnification $\times 10, \times 20, \times 40$

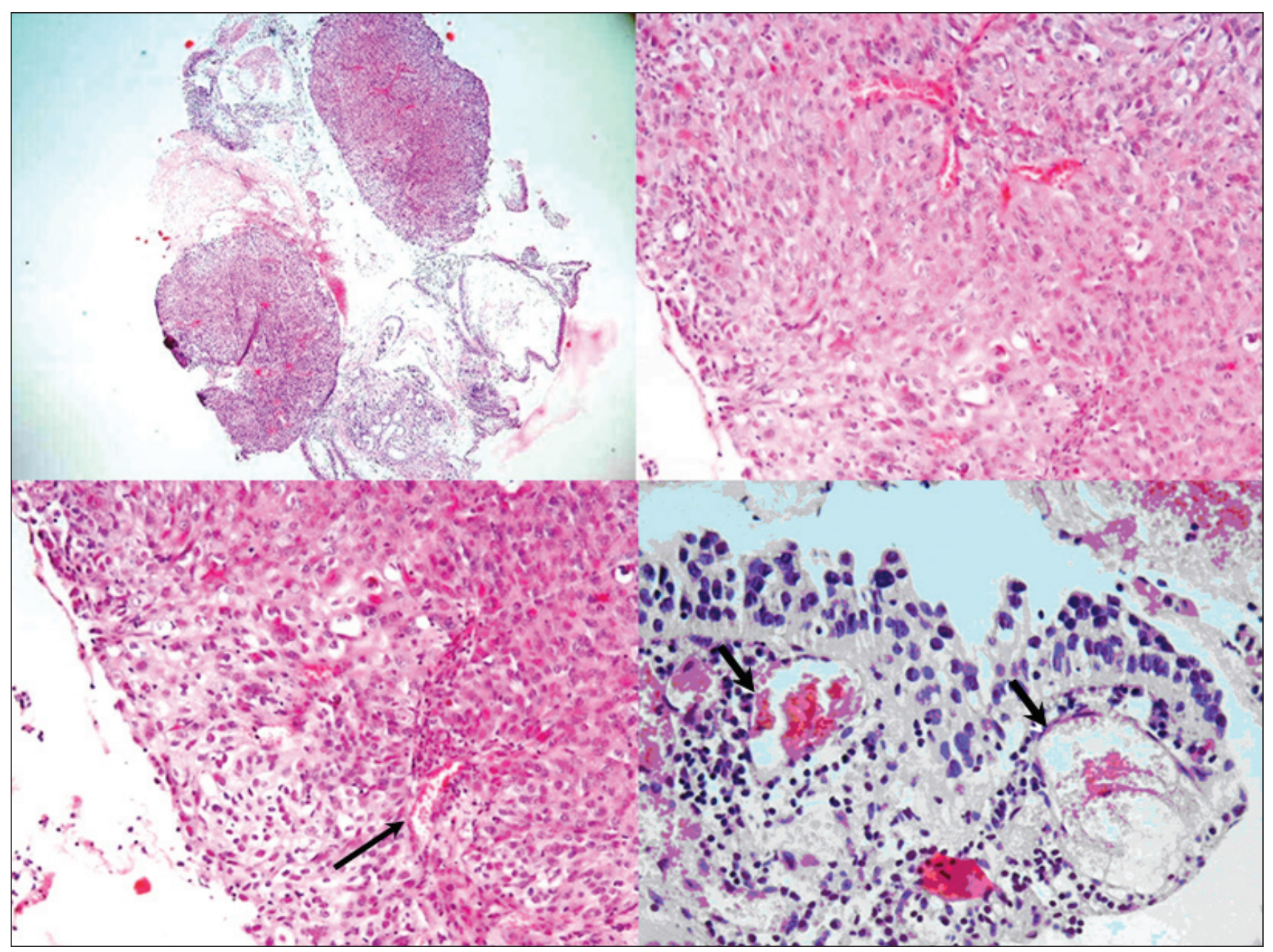

Figure 4) Both intraepithelial and juxtaposition of capillaries into dysplastic squamous epithelium associated with papillomatosis (arrow). Hematoxylin and eosin stain, original magnification $\times 10, \times 20, \times 40$

bronchoscopic methods such as AFB, narrow band imaging (NBI) bronchoscopy (18) and WLB.

Possible confounding factors that may have influenced the results of our study include using routine WLB, varying experience of the bronchoscopists and pathologists in the interpretation of bronchoscopic images and bronchial biopsies, as well as the nature of the lesions.

Premalignant airway lesions are less easily recognized and characterized than lesions in other organs. A better understanding of premalignant bronchial epithelial cell biology is necessary to recognize reliable intermediate biomarkers for screening and chemoprevention (8).
In normal tissues, a balance between angiogenesis activators and inhibitors can maintain blood vessel architecture. This balance is believed to be altered suddenly during tumorigenesis, and progenitorcells assume an 'angiogenic phenotype' stimulating the formation of new blood vessels $(19,20)$. This sudden change in tumour progenitor cells is referred to as an 'angiogenic switch' (21). Invasive tumours may show an angiogenic phenotype. However, the occurrence and timing of angiogenic switching in premalignant lesions are not well understood, especially in the airways (8).

Angiogenesis developing early in lung carcinogenesis is associatedwith overexpression of vascular endothelial growth factor (VEGF) (22). 


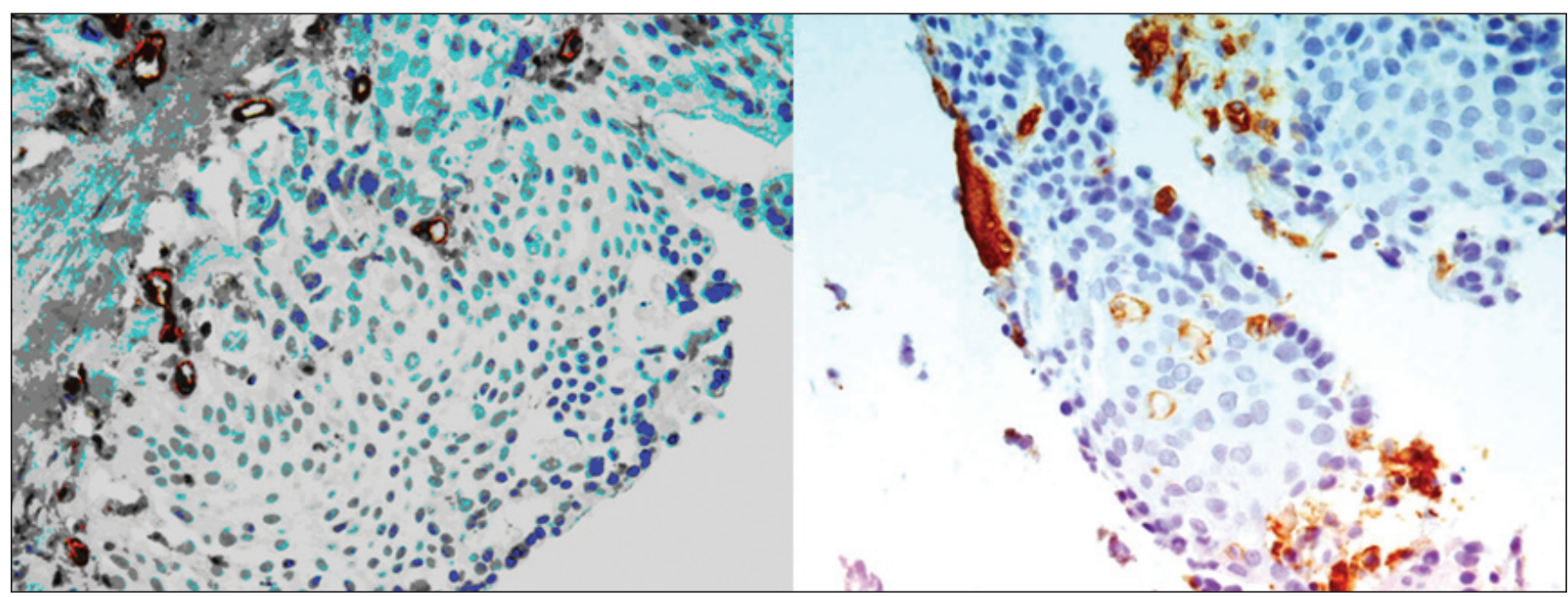

Figure 5) Immunohistochemical staining for CD31 highlights the neoangiogenesis in bronchial epithelium in angiogenic squamous dysplasia (original magnification $\times 40$ )

Collections of capillary sized blood vessels closely juxtaposed to dysplastic epithelium were easily recognizable in our histological sections stained with H\&E and highlighted by CD31 IHC staining. ASD was almost exclusively associated with dysplastic - not metaplastic squamous epithelium. These findings are in accordance with the hypothesis that there is a low microvessel count in hyperplasia and metaplasia of bronchial epithelium (23).

ASD is defined as "close juxtaposition of capillary tufts to dysplastic epithelium in the distinctive microscopic endobronchial lesion in which genetic analysis of surface epithelium in a random subset of lesions revealed loss of heterozygosity at chromosome $3 p$ in $53 \%$ of these lesions". This lesion suggests that an angiogenic stimulus may be associated almost exclusively with epithelial dysplasia in the lower airways (8).

Basement membrane thickening was not a prominent morphological feature in our ASD cases or in previous studies (8).

As a distinctive type of angiogenesis, ASD has been observed not only in lung cancers but also in high-risk smokers (8). Smoking appears to induce both a proliferative response and neovascularization in the bronchial mucosa. The projection of capillary loops into the bronchial mucosa also may be a result of neovascularization occurringwithin the lamina propria of the bronchial wall (24). Thus, it may represent an important intermediate pathological biomarker preceding lung cancer development in heavy smokers. The presence of this lesion in high-risk smokers suggests that aberrant patterns of microvascularization may happen at an early stage of bronchial carcinogenesis (8).

An association between microvessel density, VEGF expression, p53 mutations, preinvasive lesions of the bronchial tree and neo-angiogenesis have been described in early non-small cell lung cancer (25), but no confirmed $p 53$ mutations have been identified in ASD (8).

One of the most significant limitations of the present study was the lack of additional investigations such as evaluation of the expression of VEGF (receptor 2,3) on different types of the cells in ASD. It is recommended that evaluation of the gene expression of VEGF (receptor 2,3 ) be performed in future studies after detecting the lesion in bronchoscopic biopsies and staining with $\mathrm{H} \& \mathrm{E}$.

Fluorescence bronchoscopy or NBI bronchoscopy detection of ASD (18) offers great promise for early diagnosis of lung cancer, far in advance of clinical presentation (26).

In conclusion, ASD is a distinct, pre-invasive lesion and neoangiogenesis in airway mucosa, which is highly associated with bronchogenic carcinomas, especially SCC and with smoking. It should be looked for by surgical pathologists in bronchial biopsies obtained either by AFB or WLB. These findings also emphasize the role of using
AFB or other forms of bronchoscopy (eg, NBI to more effectively detect all pre-invasive lesions including ASD) and early lung cancer by bronchoscopists. More clinicopathological and molecular pathology studies should be performed to determine the long-term prognostic significance and its role in early cancer detection in high-risk smokers and chemopreventive therapeutic management of lung cancer patients.

\section{REFERENCES}

1. Miller YE, Petty TL, Lam S. The early detection of lung cancer using bronchoscopy and cytologic analysis. In: Pass HI, Carbone DP, Johnson DH, eds. Lung cancer principle and practice, 3rd edn. Philadelphia: Lippincott Williams \& Wilkins; 2005:191-4.

2. Pearson FG. Current status of surgical resection for lung cancer. Chest 1994;106:337s.

3. Spiro SG. Lung Tumours. In: Brewis RAL, Gibson GJ, Geddes DM, eds. Respiratory Medicine. London: Bailliere Tindall, 1990:832-79.

4. Babaei M, Mosavi SH, Malek M, et al. Cancer occurrence in Semnan province, Iran: Results of a population-based cancer registry. Asian Pac J Cancer Prev 2005;6:159-64.

5. Hosseini M, Adimi Naghan P, Karimi Sh, et al. Environmental risk factors for lung cancer in Iran: A case-control study. Int J Epidemiol;2009;38:989-96.

6. Travis WD, Colby TV, Corrin B, et al. Histologic typing of tumors of lung and pleura. In: Sobin LH, ed. World Health Organization international classification of tumours, 3rd edn. New York: Springer-Verlag, 1999.

7. Raica M, Cimpean AM, Ribatti D. Angiogenesis in pre-malignant conditions. Eur J Cancer 2009;45:1924-34.

8. Keith RL, Miller YE, Gemmill RM, et al. Angiogenic squamous dysplasia in bronchi of individuals at high risk for lung cancer. Clin Cancer Res 2000;6:1616-25.

9. Hirsch FR, Franklin WA, Gazdar AF, et al. Early detection of lung cancer: Clinical perspectives of recent advances in biology and radiology. Clin Cancer Res 2001;7:5-22.

10. Muller KM, Muller G. The ultrastructure of preneoplastic changes in bronchial mucosa. Curr Top Pathol 1983;73:233-63.

11. Cavarga I, Kocan P, Boor A, et al. Immunohistochemical markers of proliferation and vascularisation in preneoplastic bronchial lesions and invasive non-small cell lung cancer. Neoplasma 2009;56:414-21.

12. Keith RL, Miller YE, Kennedy TC, et al. Angiogenic squamous dysplasia (ASD): A biomarker highly associated with squamous cell lung carcinoma [abstract]. Lung Cancer 2003;41:S161.

13. Nicholson AG, Perry LJ, Cury PM, et al. Reproducibility of the WHO/IASLC grading system for pre-invasive squamous lesions of the bronchus: A study of inter-observer and intra-observer variation. Histopathology 2001;38:202-8.

14. Corrin B, Nicholson AG. Pathology of the Lungs, 2nd edn. London: Churchill Livingstone (Elsevier), 2006:531-2. 
15. Pass HI, Carbone DP. Principles \& Practice of Lung Cancer, 3rd edn. Philadelphia: Lippincott Williams \& Wilkins 2005:233.

16. Cagle PT, Allen TC, Kerr KM. Transbronchial and endobronchial biopsies. Wolters Kluwers: Lippincott William \& Wilkins 2005:35.

17. Qu J, MacAulay C, Lam S, et al. Optical properties of normal and carcinoma bronchial tissue. Applied Optics 1994;33:7397-405.

18. Herth F J F, Eberhardt R, Anantham D, et al. Narrow-band imaging bronchoscopy increases the specificity of bronchoscopic early lung cancer detection. J Thorac Oncol 2009;4:1060-5.

19. Folkman J. Tumor angiogenesis. In: Mendelsohn J, Howley PM, Israel MA, et al, eds. The Molecular Basis of Cancer. Philadelphia: WB Saunders Co, 1995:206-32.

20. Bouch N, Stellmach V, Hsu SC. How tumors become angiogenic. Adv Cancer Res 1996;69:135-74.

21. Hanahan D, Folkman J. Patterns and emerging mechanisms of the angiogenic switch during tumorigenesis. Cell 1996;86:353-64.
22. Merrick DT, Haney J, Petrunich S, et al. Overexpression of vascular endothelial growth factor and its receptors in bronchial dypslasia demonstrated by quantitative RT-PCR analysis. Lung Cancer 2005;48:31-45.

23. Fontanini G, Vignati S, Bigini D, et al. Neoangiogenesis: A putative marker of malignancy in non-small-cell lung cancer (NSCLC) development. Int J Cancer 1996;67:615-9.

24. Hiroshima K, Iyoda A, Shibuya K, et al. Evidence of neoangiogenesis and an increase in the number of proliferating cells within the bronchial epithelium of smokers. Cancer 2002;95:1539-45.

25. Fontanini G, Calcinai A, Boldrini L, et al. Modulation of neoangiogenesis in bronchial preneoplastic lesions. Oncol Rep 1999;6:813-7.

26. Tockman MS. Lung cancer: Chemoprevention and intermediate effect markers. IARC Sci Publ 2001;154:257-70. 


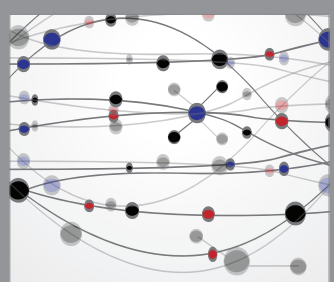

The Scientific World Journal
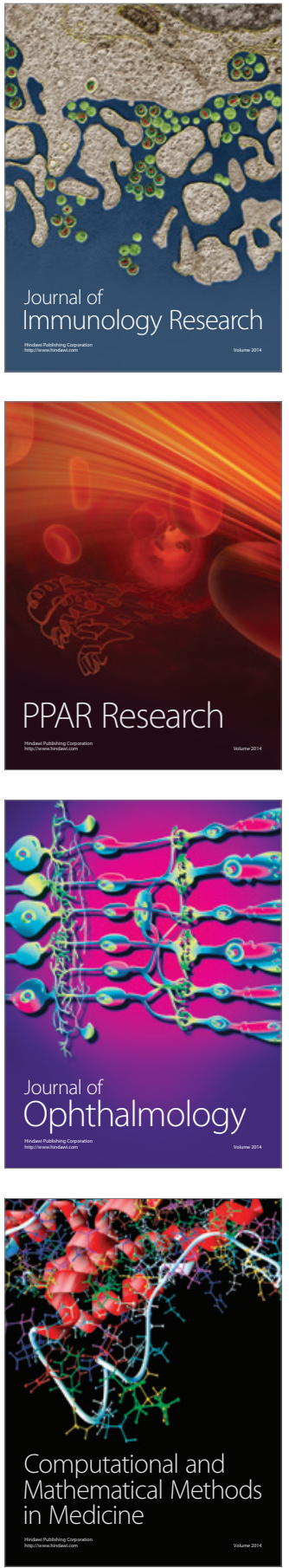

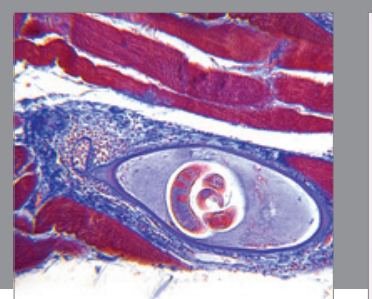

Gastroenterology Research and Practice

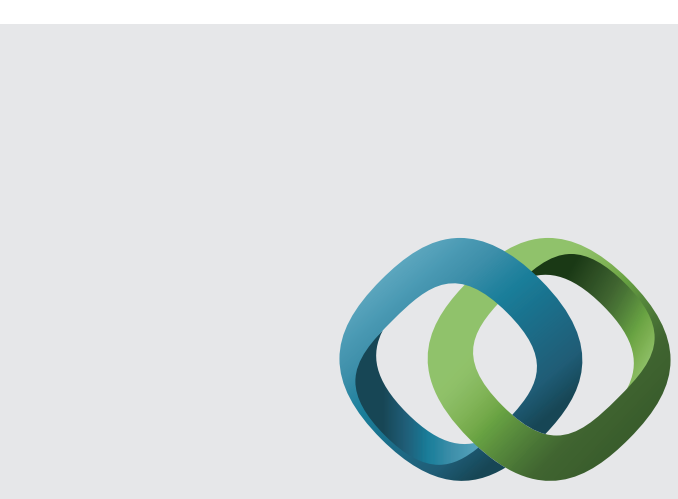

\section{Hindawi}

Submit your manuscripts at

http://www.hindawi.com
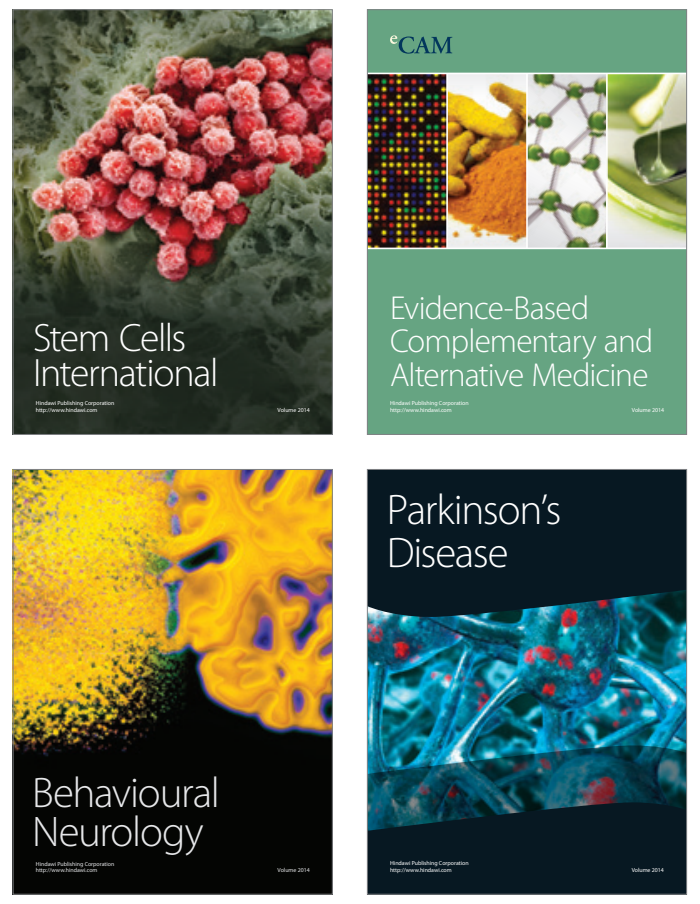
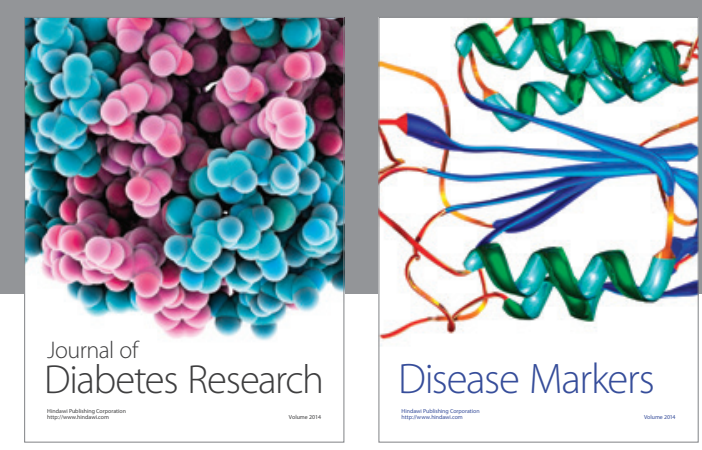

Disease Markers
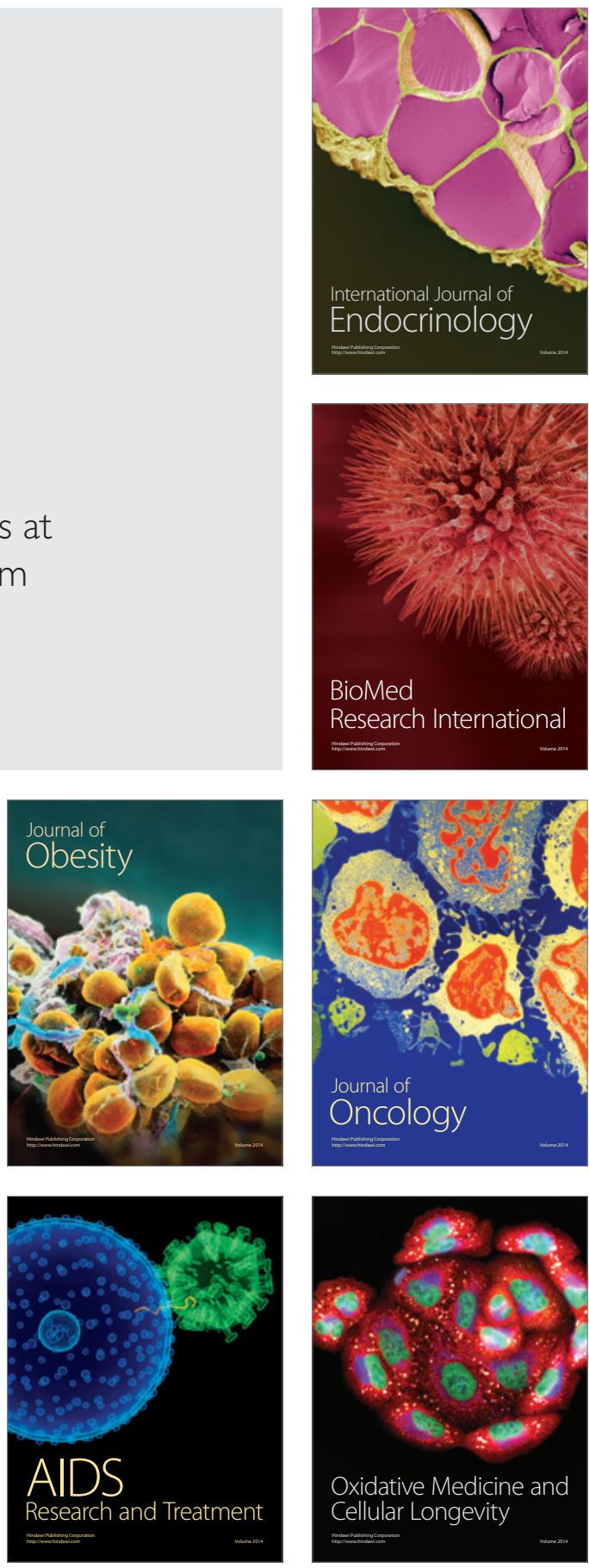